\title{
WHETHER BITCOIN, CRYPTOCURRENCIES AND BLOCKCHAIN SUITABLE FOR SOCIAL ECONOMIC DEVELOPMENT IN EMERGING MARKETS IN TECHNOLOGY ERA

\author{
SYLWIA GWOŹDZIEWICZ ${ }^{1}$, DINH TRAN NGOC HUY ${ }^{2}$, PHAM VAN HONG ${ }^{3} \&$ PHAN ANH $^{4}$ \\ ${ }^{1}$ Jacob of Paradies University in Gorzow Wielkopolski, Poland \\ ${ }^{2}$ Banking University HCMC, Ho Chi Minh City Vietnam, International University of Japan, Japan \\ ${ }^{3}$ Vietnam Institute of Science, Technology and Innovation, Hanoi Vietnam \\ ${ }^{4}$ Banking Academy of Vietnam
}

\begin{abstract}
Normally, the development or issuing new currencies to the market need to be guaranteed by the suitable amount of goods or products or services to control inflation well. Therefore, in this paper, we analyze and evaluate the positive and negative of Bitcoin as well as cryptocurrencies, beyond the presence of a central bank. Experiences of other countries such as the United States, Japan, China or the developed countries of the European Union and consequences for the economy became a lesson for well as developing countries. Proper solutions and development orientation as well as risk management for Bitcoin and cryptocurrencies is essential to ensure the role of cryptocurrencies in supply chain financing, in providing effective payment channels, and addressing deficiencies of the commercial banking system. The safety for users and participants in these platforms, and whether crytocurrencies facilitate money laundering and financial crimes is an issue that needs to be discussed, towards the topic of sustainable development for the shadow banking system, thereby contributing to social security, creating diversification of payment and capital to support production and business, thus contributing to the reduction of the rich-poor discrepancies. Blockchain technology, DLT (Distributed Ledger Technology), because of its development through cryptocurrency financial systems, is evolving on further implications in the development of systems in Industry 4.0 around the world. From year to year, many important cross-border and global blockchain consortia and councils are created in the world. They are aimed at developing, supporting experiences, as well as practical application, and implementation of blockchain technology. These institutions are based mainly in the USA, Great Britain, Japan, Canada, China, Luxembourg, and Dubai (eg Blockchain Embassy Asia or Global Blockchain Council - Dubai).
\end{abstract}

KEYWORDS: Bitcoin, Cryptocurrencies, Electric Money, Virtual or Digital Currency, e-Commerce, Blockchain, Technology Era, Policies, Sustainable Development, ICT Technology Law

JEL: $011,018,020$

Received: Jun 08, 2020; Accepted: Jun 28, 2020; Published: Aug 28, 2020; Paper Id.: IJMPERDJUN2020923

\section{INTRODUCTION}

The commercial banking systems in recent years have played an important role in developing all aspects of the economy.

Besides, there is still a shadow banking system and peer-to-peer lending. P2P lending operations platforms vary in type and manner of implementation. 
Also, there are arguments on roles of cryptocurrencies such as Bitcoin, whether or not it is suitable for emerging markets such as Vietnam, Myanmar, Indonesia, Latin America, Africa, etc. It is one main purpose of this study.

The paper is organized as follows: after the introduction, it is the research issues, reviewing and comparing previous studies. Next, part 3 will include methodology and data and part 4 will present the main research results. Section 5 provides us with some policy discussion, conclusions and recommendations that will be covered in section 6 while section 7 covers IT solutions for risk management, part 8 - the future of legal blockchain solutions.

\section{RESEARCH CONTENTS}

\section{Research Issues}

The scope of this study will include:

- Research issue 1: Whether it is suitable, the role of Bitcoin and cryptocurrencies in a developing economy - the case of Vietnam

- $\quad$ Research issue 2: Risks and mitigation measures, risk management in operating Bitcoin platform.

This paper also examines the following two (2) hypotheses:

- Hypothesis 1: Bitcoin and cryptocurrencies will help to reduce the rich-poor discrepancies, the urban-rural gap.

- Hypothesis 2: Bitcoin can be managed and controlled to benefit the economy.

\section{Previous Studies}

Pozsar et al. (2010) proposed that increasing capital and liquidity standards for depository and insurance companies would be able to improve the profitability of shadow banking. Therefore, shadow bank (Shadow), in one form or another, is expected to be an important part of the financial system in the near future. Then Vishny et al. (2011) mentioned that under reasonable expectation, the shadow banking system will stabilize and improve welfare. However, when investors and intermediaries ignore risks at a later stage, the expansion of risk lending and the concentration of risks in financial intermediaries create financial weakness and volatility over time.

E-commerce uses a range of payment methods that best suit the diverse preferences of consumers, the specifics of each transaction and the attributes of the product (H. Allen, 2003; Committee on Payment and Settlement Systems, 2012; Zhang \& Li, 2006). A common feature of these payment systems is the presence of a trusted third party, who processes the transaction. Until recently, there was no widely-available equivalent to cash in e-commerce, even though the need for some form of electronic money to perform this role was clear, especially in the area of micro-payments (Chaum, 1983; Kauffman \& Walden, 2001).

Beside, Peters et al. (2015) stated centralised virtual currencies, usually for the purpose of transacting in social and gaming economies, and crypto-currencies, which aim to eliminate the need for financial intermediaries by direct peerto-peer online payments.

Giungato et al. (2017) mentioned from the analysis it emerges that the transition of the whole monetary system in the new cryptocurrency will result in an unacceptable amount of energy consumed to mine new bitcoins and to maintain 
the entire virtual monetary system, and probably bitcoin will remain a niche currency. Blockchain, which is the base for a distributed and democratically-sustained public ledger of the transactions, could foster new and challenging opportunities.

Next, Damodaran (2018) mentioned first, bitcoin miners, who function as neo-Spinozian multitudes, squarely challenge the prerogative of the State to issue fiat money. Second, these distributed communities usher in a new philosophy of time in order to measure their mining efforts objectively. Third, these communities change the existing state of affairs by linking bitcoin earnings to 'proof of work'. Hsieh et al. (2018) described that Bitcoin represents the first real-world implementation of a "decentralized autonomous organization" (DAO) and offers a new paradigm for organization design. Imagine working for a global business organization whose routine tasks are powered by a software protocol instead of being governed by managers and employees. Task assignments and rewards are randomized by the algorithm. Information is not channeled through a hierarchy but recorded transparently and securely on an immutable public ledger called "blockchain." Further, the organization decides on design and strategy changes through a democratic voting process involving a previously unseen class of stakeholders called "miners."

Then, Christian (2019) mentioned that Cryptocurrencies, like bitcoin, raise new legal questions due to their innovative technological concepts. While academic research covers nearly all areas of the technological concepts of those currencies, legal studies focus only on a few topics. The papers that have been published so far discuss mainly economic law, tax law, and financial regulations. Spithoven (2019) conclude that Bitcoin falls short in its self-governing ambitions, while cryptocurrency software protocols and blockchain technologies have potentialities within "permissioned" peer-topeer private or hybrid networks. However, regulation and supervision by trusted third parties are required. Moreover, Yuneline (2019) pointed that regarding the characteristic of money, cryptocurrency is acceptable. But in terms of the legal perspectives, cryptocurrency does not meet the criteria as currency. From the economic perspective, cryptocurrency does not fully meet the characteristic currency due to high price volatility, and from the Sharia perspective, cryptocurrency can be considered property (mal) but not as a monetary value (thamanniyah).

And Giudici (2020) posit that cryptocurrencies may perform some useful functions and add economic value, but there are reasons to favor the regulation of the market. While this would go against the original libertarian rationale behind cryptocurrencies, it appears a necessary step to improve social welfare.

So far, many studies have been done in this Bitcoin and cryptocurencies area, however, this article provides specific recommendations for emerging markets such as Vietnam based on an analysis of lessons learned by Bitcoin and cryptocurrencies in countries around the world including USA, China, Japan.

\section{METHODOLOGY}

This research paper uses qualitative research and analysis methods, logical analysis, deduction and synthesis to provide direction and solutions, dialectical materialist methods combined with historical materialistic methods. consider assessing phenomena, things, economic objects, inductive interpretation methods and evidences in the economy to contribute to economic reality.

In addition, this paper uses general data analysis methods and draws lessons from other countries to comment on the results, then propose policies based on these analyzes. 


\section{MAIN FINDINGS}

\section{Overview of Bitcoin and Cryptocurrencies}

Some cryptocurrencies use Blockchain technology:

There are currently more than 2500 cryptocurrencies worth of milions or even billions of USD in transactions. And Korea, Singapore, US, Europe, Latin America, etc. have regulated Bitcoin, Blockchain and digital currencies, as well as taxation issues. Bitcoin, Litecoin and Ethereum are among strong digital currencies until now. Price index of Bitcoin which is an average number of Bitcoin price across global exchanges, as shown in the below figure, reached 9164 USD in June 2020.

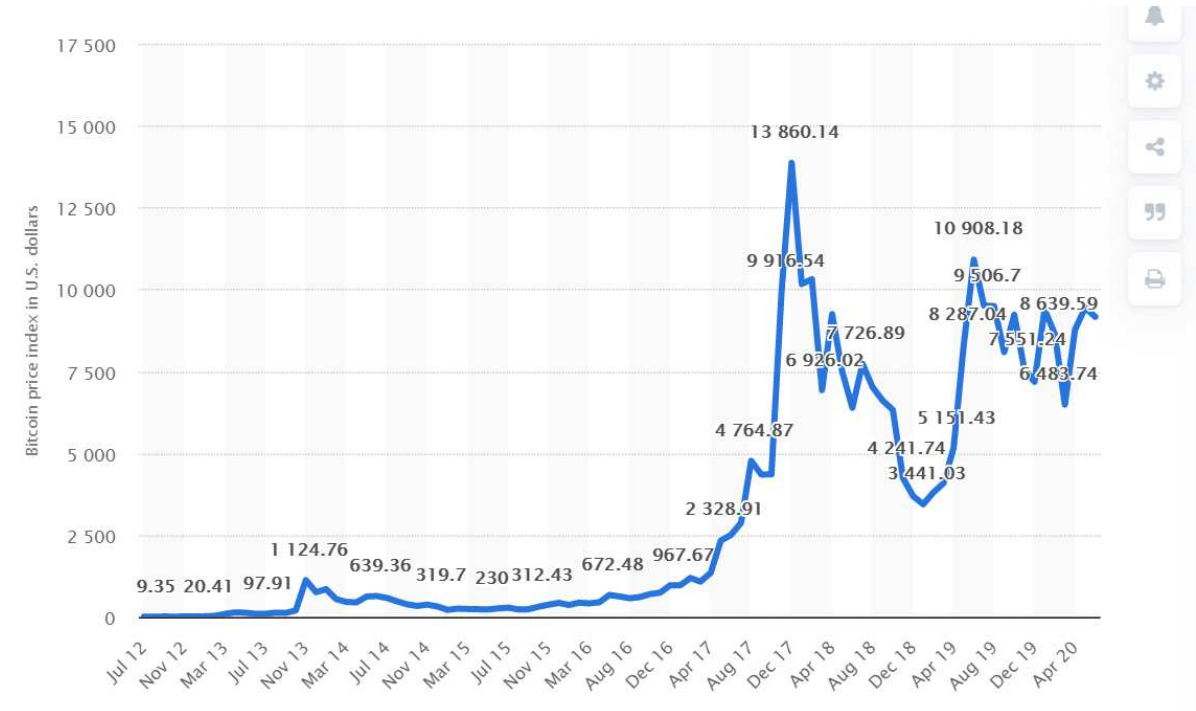

Figure 1: Bitcoin Price Index in USD till June 2020.

Another cryptocurrency, Ethereum, has price index reaching 225.71 USD till June 2020, shown in the below chart:

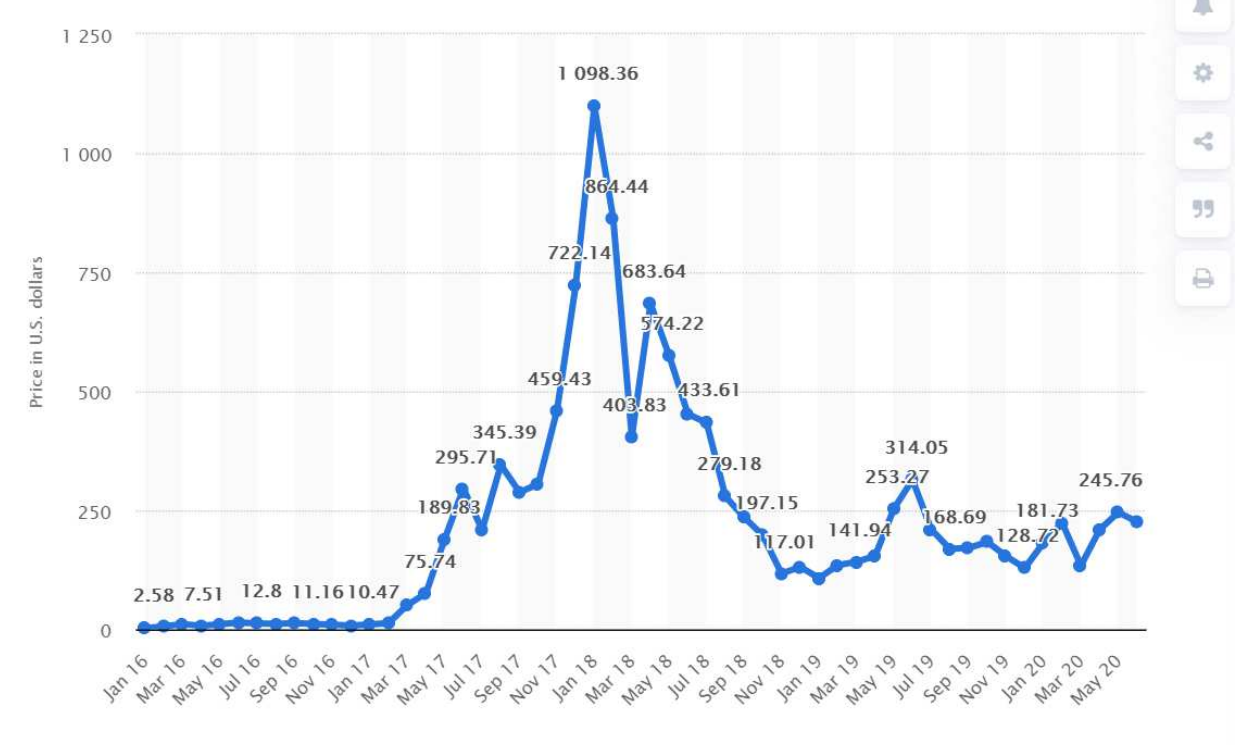

Figure 2: Price of Ethereum in USD till June 2020. 
According to statista.com (see below figure), the number of wallet users has been increasing up to more than 50 million users in June 2020.

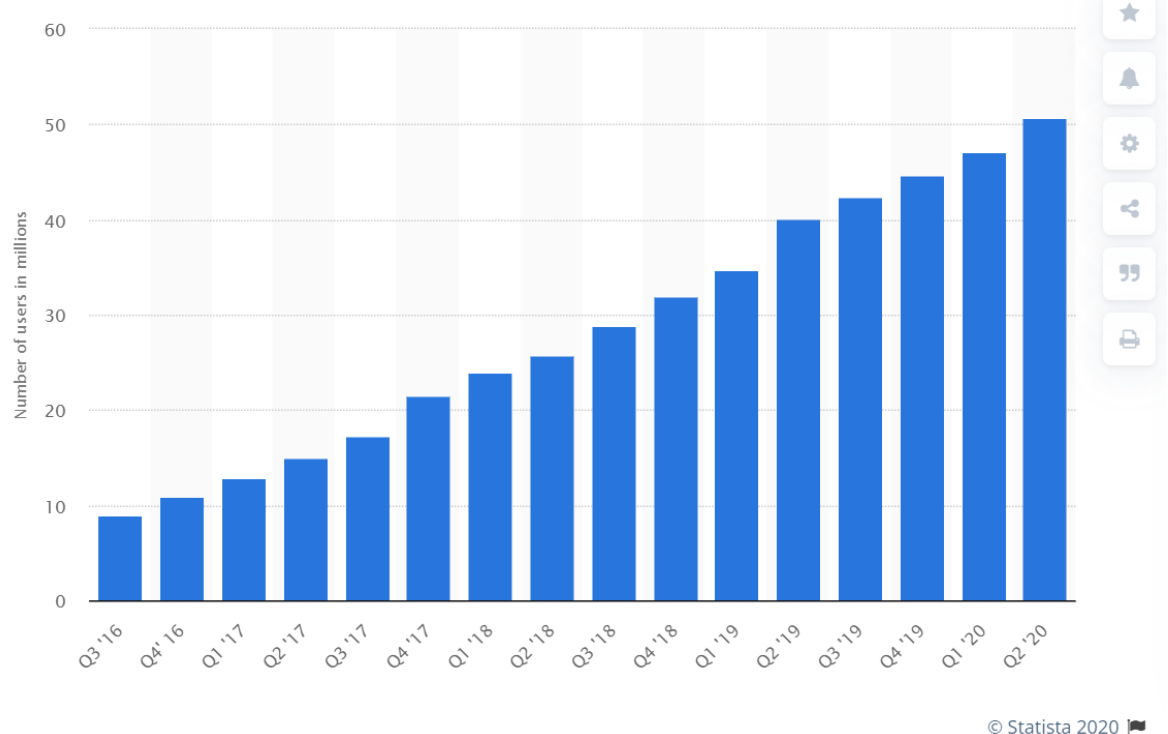

Figure 3: Number of Blockchain Wallet users Worldwide.

\section{Pros and Cons of Bitcoin}

We also perform a SWOT analysis on Bitcoin and cryptocurrencies as follows:

\section{Opportunities}

- Providing additional options other than traditional banks for investors;

- It effectively conducts effective online payment channels for users for water, electricity, mobile, internet, utilities bills ;

- It provides credit to the economy in the event that normal banks are in a bad state, thus helping to alleviate credit hunger;

\section{Threats}

- Potential risks if platform collapses;

- Risk happening if users losses their access key to accounts;

- Viruses might attack accounts;

- High risks if hackers enter platform and steal online data;

- High risks if bad people use bitcoin as a mean for money laundering when buying and selling it;

\section{Strengths}

- Providing payment options at a low transaction cost (no staff fee, just platform operating fee);

- If regulated and controlled well, Can help to increase output, e-commerce, online payment and GDP growth; 


\section{Weaknesses}

- Need to establish sound legal framework and regulation before Bitcoin accepted;

- It needs high security software to protect data;

- There are other risks analyzed below;

Anyway Bitcoin is the most valuable cryptocurrency, developed by Satoshi Nakamoto since 2009 and its market price has increased rapidly till 2017 shown in below chart:

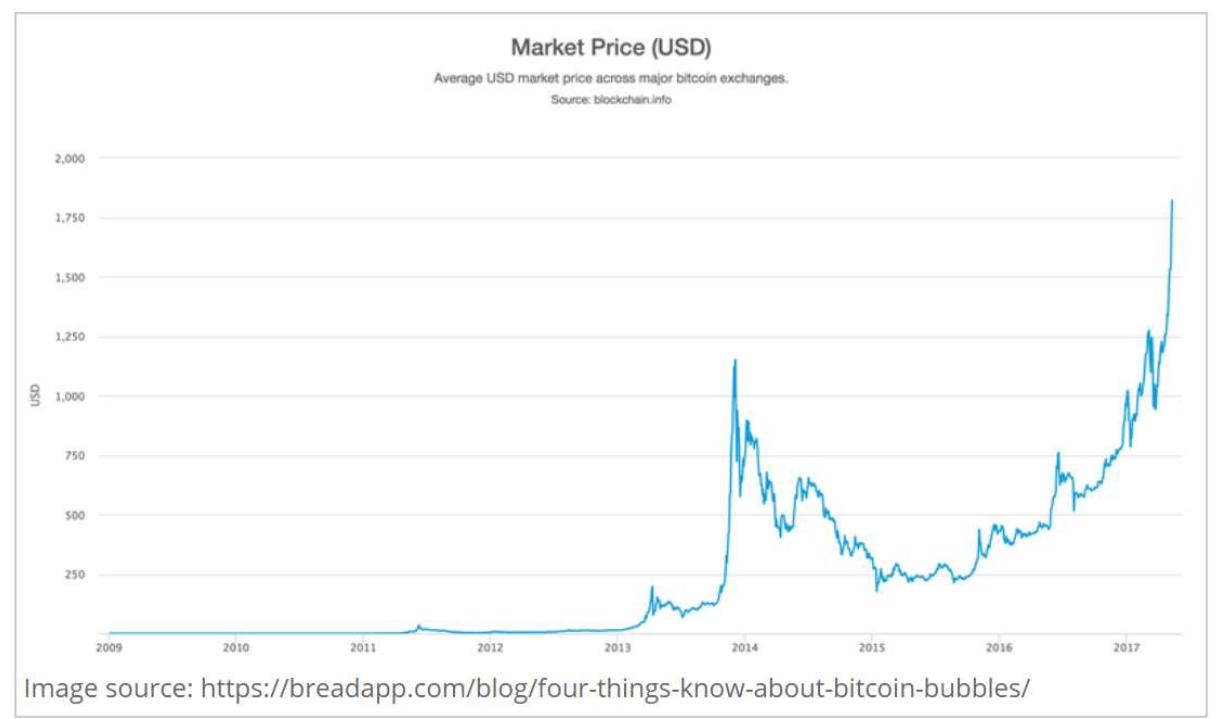

Figure 4: Bitcoin Price Increase from 2009-2017.

\section{Risk Analysis of Bitcoin and Cryptocurrencies}

When we accept Bitcoin and other cryptocurrencies in circulation, he total amount of currencies will increase and put threats on inflation, if there is no amount of goods, products or services attached.

As we see in the below famous formula, from Monetarist theory and Keynesian ideas:

$\mathrm{M} \times \mathrm{V}=\mathrm{P} \times \mathrm{Q}$

If money supply (M) increases, inflation increases through price factor $(\mathrm{P})$, then nominal interest rate will increase and NOT a benefit fr borrowers and consumers (see Fisher equation below): 


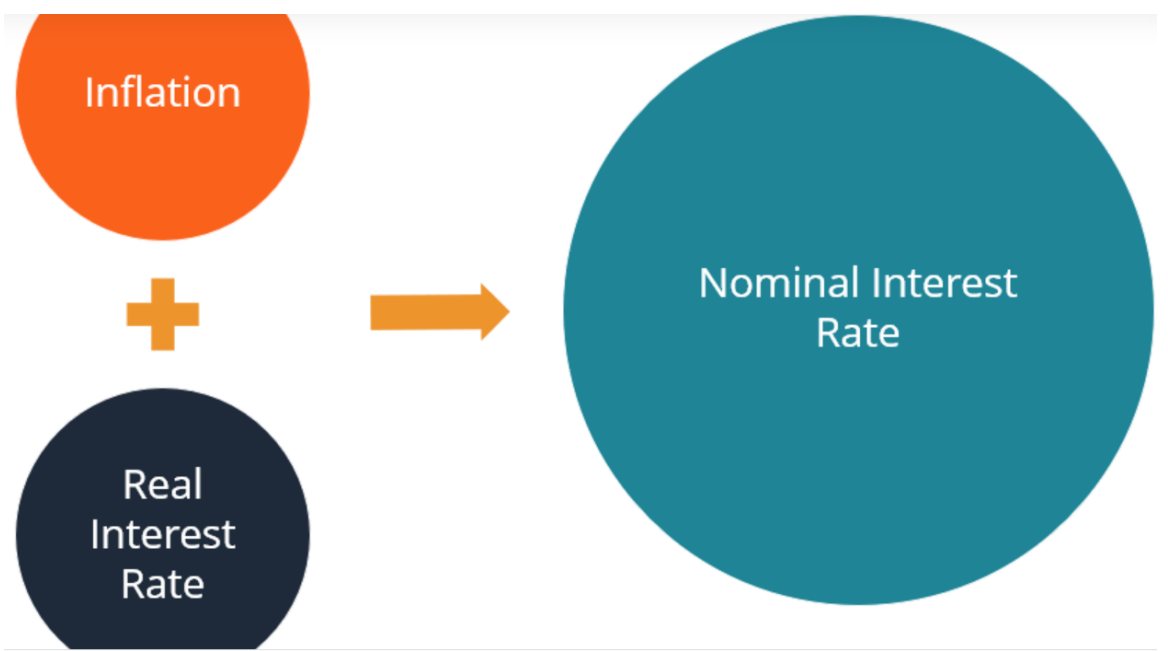

Hence, we need Q increases parallel with Money supply and Velocity (V) to balance economy and keep price stable.

Next, we go to further analysis on monetary theories:

In order to make money supply rationally (via cryptocurrencies and bitcoin supply) we need to facilitate a proper mechanism, for instance:

Cryptocurrencies and bitcoin supply -> Money supply increases ->Investment increases to reduce urban-rural discrepancies -> Amount of goods, products and services increase -> GDP increases while stable price -> full employment under legal framework governing cryptocurrencies -> rich-poor gap reduction -> reaching socio-economic-environmental goals.

\section{Regulation of Cryptocurrencies in Some Countries}

In Japan, in April 2017, cryptocurrencies are under Payment Service Act, in which it regulated Money Laundering as follows: "The cryptocurrency exchange businesses are obligated to check the identities of customers who open accounts, keep transaction records, and notify authorities when a suspicious transaction is identified". Market will adjust itself and some cryptocurrencies exchange businesses will be suspended if people loss much money (see an example of Coincheck lost $400 \mathrm{~m}$ USD in tokens).

In the US, there is Blockchain regulations and in Europe, cryptocurrencies businesses have to register with authorized financial agencies. Cryptocurrencies taxation is another matter taking into account.

Other countries such as Argentina, France, Switzerland, Brazil, has regulated cryptocurrencies, except China prohibited bitcoin since 2013. In case of Lithuania, cryptocurrencies exchange must register with Ministry of Finance.

\section{Regulatory Issues of the "Virtual Currency" in the European Union}

The European Union constantly monitors the development of the global financial market as well as new trends related to cryptocurrencies. According to the European Parliament, the planned legal changes will concern, inter alia:

- Increasing supervision over cryptocurrency trading,

- Transparency of the cryptocurrency market, 
- Counteracting money laundering and other crimes,

- Eliminate improper activities related to cryptocurrencies,

- The possibility of using cryptocurrency technology for global payment settlements.

The regulation of cryptocurrencies in the Member States of the European Union directly depends on the introduction of these regulations at the European Union level. On the example of Bitcoin, it can be concluded that it should have a range of occurrence and law enforcement in all major areas of law, i.e. civil, administrative, criminal, financial. The pursuit of a detailed qualification of Bitcoin in each branch of the law may lead to the fact that the legal status of bitcoin will not be uniform, a universal understanding of bitcoin will not be possible. There is no official and universal legal classification for bitcoin. In Poland, as in most European Union member states, the references of the authorities and their representatives to bitcoin and other cryptocurrencies mainly concern tax interpretations, as well as verification whether bitcoin is subject to existing law. Until 2018, several tax interpretations were issued in Poland covering bitcoin and other cryptocurrencies. They indicate that:

- For tax purposes, the income from the sale of bitcoin is income from property rights, and income from property rights is accumulated with other income; The income obtained from the sale should be taxed on general principles, i.e. according to the tax scale.

- Bitcoins do not have the power to cancel obligations given by the legislator unless payments are made to entities that accept this form of payment; in the case of bitcoin payments for goods or services, a barter agreement takes place;

- The transfer to third parties of "electronic Bitcoin money vouchers" will constitute an activity subject to VAT as a paid service, although this service of transferring electronic bitcoin money vouchers will not be classified as VAT-exempt financial services, which results in double taxation of the value-added tax and bitcoin payment transaction services;

- Bitcoin serves only as an alternative means of payment for official currencies (zloty, euro, dollar) and the settlement is based on a contract;

- Bitcoin is bound by property law. The sale of property rights is associated with the obligation to pay tax on civil law transactions on general principles and taxation with the tax on goods and services as the provision of services.

It is also worth noting that one of the first official acts that in the Polish state provide a general definition of "virtual currency" is the Polish Act of March 1, 2018 on counteracting money laundering and financing of terrorism (Dz.U. 2018 poz. 723). According to Art. 2 clause 2 point 26 of the cited act, a "virtual currency" is understood as a digital representation of a value that is not:

- Legal tender issued by the National Bank of Poland, foreign central banks or other public administration bodies,

- An international unit of account established by an international organization and accepted by countries belonging to this organization or cooperating with it,

- Electronic money within the meaning of the Act of 19 August 2011 on payment services, 
- A financial instrument within the meaning of the Act of July 29, 2005 on Financial Instruments Trading,

- Bill or check - and is exchangeable in the course of trade for legal tender and accepted as a medium of exchange, and maybe electronically stored or transferred, or traded in e-commerce.

As a result of the introduction of the definition of "virtual currency", there had to be legislative tax changes as well. Polish Act of 23 October 2018 on the amendment the Personal Income Tax Act, the Corporate Income Tax Act, the Tax Ordinance Act and some other acts (Dz. U. z 2018 r. poz. 2193, 2500, z 2020 r. poz. 1065.) changed the moment of the emergence of income on the cryptocurrency market in Poland. In art. 17 (1f) of the cited act, a provision was introduced that "the sale of virtual currency shall be understood as the exchange of virtual currency for legal tender, goods, service or property rights other than the virtual currency or the settlement of other liabilities with a virtual currency". Since there are no detailed regulations, it was assumed that revenues from the sale of cryptocurrencies should be included in the sources of income and settled annually according to the general tax scale - $18 \%$ or $32 \%$. The income limit is approx. PLN 85.5,000 (approx. EUR 380,000). For a business involving trading in cryptocurrencies, it is possible to be taxed $19 \%$ flat tax.

In the European Union, the regulation of cryptocurrencies is primarily about combating their possible use for criminal activities, which is why they are covered by the provisions of the European Union Member States through the implementation of Directive (EU) 2015/849 of the European Parliament and of the Council of 20 May 2015 on the prevention of the use of the financial system for the purposes of money laundering or terrorist financing, amending Regulation (EU) No 648/2012 of the European Parliament and of the Council. Therefore, in connection with this Directive, similar legal provisions concerning the "virtual currency" have been introduced in the European Union countries, as shown in the example of Poland. Regulations under "virtual currencies" will also seek to ensure a greater degree of protection of consumers and investors in this market, eg by imposing disclosure obligations on companies operating in this industry. Cryptocurrency market representatives suggest that regulations must take into account the great innovative potential of cryptocurrencies, DLT/blockchain technology, and the early stage of market development. They should also be synchronized with the policy of promoting innovation, including financial innovation. Supporters of "virtual currencies" warn against regulations that may limit legal activity and stop the development of innovation. The fundamental factor behind the emergence of cryptocurrencies was the desire to create a decentralized monetary structure. Considering that the factors shaping the functioning of the cryptocurrency sector may undergo drastic changes, good regulatory systems must efficiently and quickly respond to the market environment. The rapidly changing market and the rapid development of cryptocurrencies mean that proper regulation of this sector requires cooperation with industry representatives, coordination of legislative activities between different countries, and transparent information strategies about threats addressed to the public.

Cryptocurrency and virtual currencies are not identical, but separate concepts. Virtual money does not belong to electronic money and, by its financial and legal nature is the internal electronic currency of network communities-social networks, virtual worlds, and online games, and its use is limited to the acquisition and sale of virtual goods within the network community. Thus, the use of cryptocurrency in international practice indicates that countries have different attitudes towards their introduction into circulation. This is due primarily to the novelty of this tool and the lack of a single definition of the category of "cryptocurrency", which revealed its essence. A positive attitude to bitcoins is typical for developed countries, and in developing countries, there are some limitations in this field (Dniprov O. et all; 2019). 


\section{DISCUSSION AND FUTURE RESEARCH DIRECTIONS}

\section{Experience and Lessons from Bitcoin in Japan}

Japan is a global leader in Bitcoin and cryptocurrencies development, who has legal framework regulating cryptocurrencies activities and utilizes technology for innovation in such financial products. However, around 6. 2millionworth of cryptocurrency was hacked from exchange accounts, according to Japanese news source Nikkei.

According to statistics, there are $31.4 \%$ of people joining in survey knowing about Bitcoin as follows:

Level of awareness of bitcoins in Japan as of October 2017

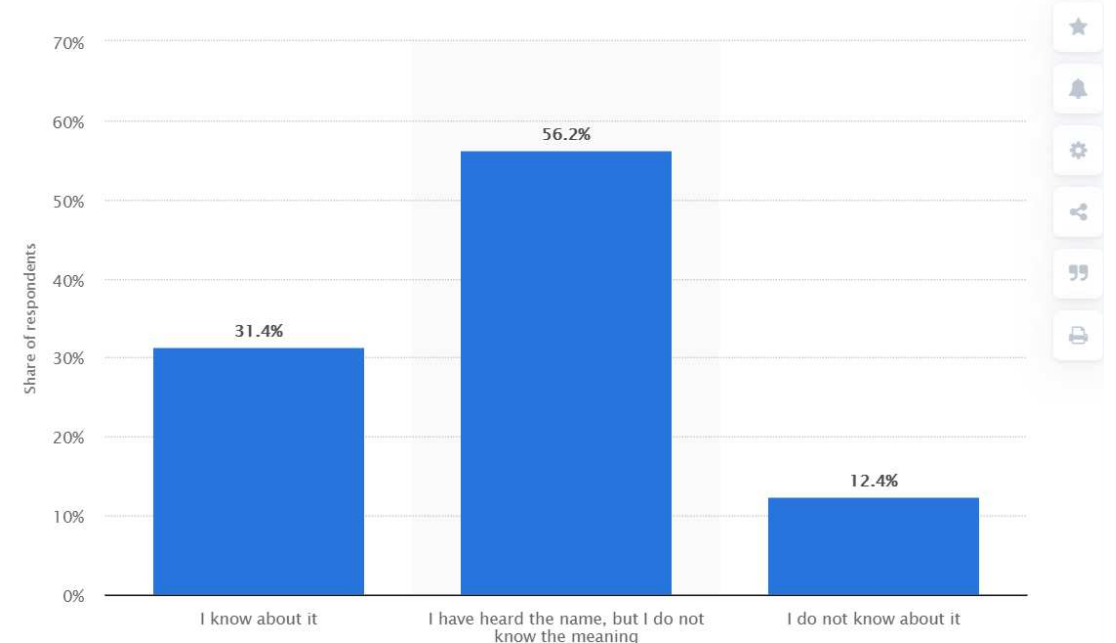

Figure 5: Level of Bitcoin Awareness in 2017 (Source: www.statista.com).

\section{Experience and Lessons from Bitcoin in Other Countries}

In many countries such as Turkey and others, many people use cryptocurrencies as presented in following figure:

\section{How Common Are Crypto Currencies Around the World?}

Share of respondents who said that they used or owned crypto currencies

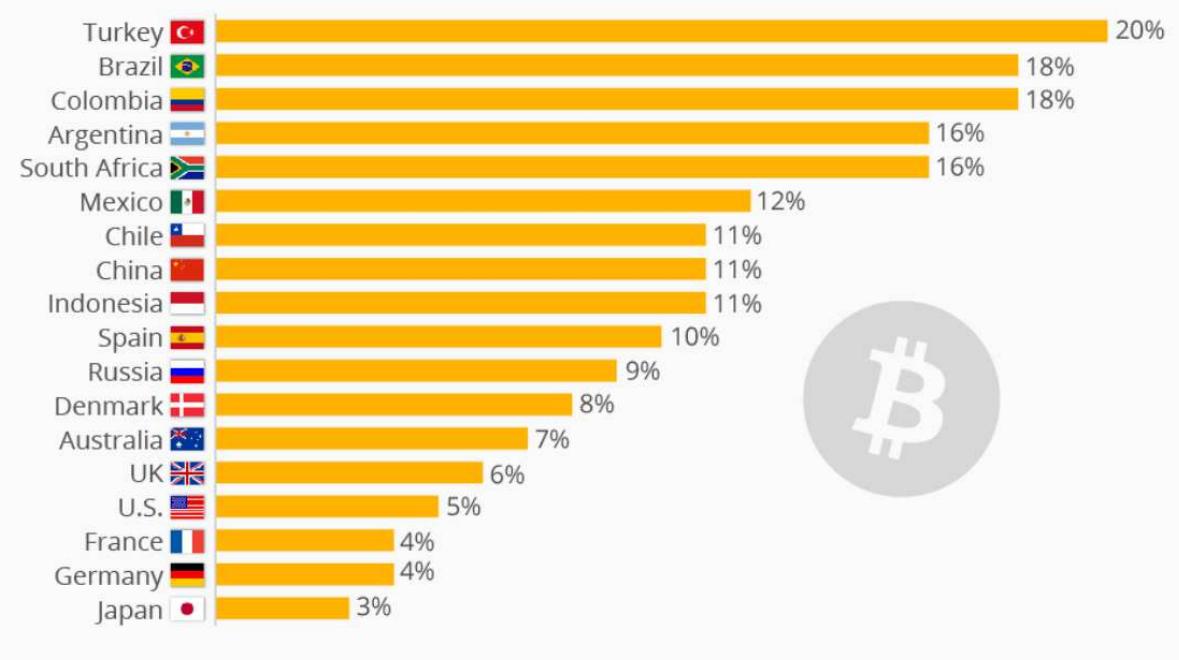

cc) (1) $\rightleftharpoons$ Selected countries, around 1,000 respondents per country surveyed in 2019

estatistacharts Source: Statista Global Consumer Survey

Figure 6: Cryptocurrencies becoming more Popular in the World. 
Hence, we can see many users in Latin America, European developed countries used cryptocurrencies.

\section{CONCLUSION AND POLICY RECOMMENDATIONS}

In this section, we will propose digital currencies plans for emerging markets including, bit not limited to Vietnam. It is the time we go beyond traditional payments of banking functions.

\section{Conditions to Develop Bitcoin Platform}

- Blockchain technology: maintaining safe technology with high security, risk management solutions need to be attached with wallets and accounts, more than $99 \%$ of cases out of hackers' intervention.

- Bitcoin is another kind of e-currency, and need to be ensured by a suitable amount of goods or services, otherwise it will cause inflation happening. Goods or services can be any kinds or forms such as physical goods or products, real estates, services, etc...that can create value added for society.

Hence, The development of Bitcoin and just a few cryptocurrencies can be done via suitable mechanisms:

Cryptocurrencies and bitcoin supply -> Money supply increases ->Investment increases to reduce urban-rural discrepancies -> Amount of goods, products and services increase -> GDP increases while stable price -> full employment under legal framework governing cryptocurrencies -> rich-poor gap reduction -> reaching socio-economic-environmental goals.

This progress needs to be done and controlled slowly but ensure no high inflation and price, full employment and reduce much depending on bank system. It is vital to connect digital currency with goods, products, real estate and services exchange to ensure the public get benefits from such e-money.

Then the next step is connecting bitcoin and digital currencies with e-commerce, i.e online payment. Then it will help to increase output, production, profits, sales and GDP growth. And that's why Bitcoin can help the economy to overcome recession from commerce war and Covid 19 or other diseases and disasters.

Using Bitcoin to increase $\mathrm{V}$ (velocity of money) for more e-commerce and online payment is under consideration.

Last but not least, Bitcoin needs to be controlled under the effective coordination of many governmental bodies such as: Cyber security and international or national crime prevention agencies, Ministry of Finance and Central Bank, Interpol, etc. And Legal procedures for it need to be done at least around 1 year ahead of implementation stage.

When people invest into Bitcoin and others, they need to make sure it is beneficial through investment channels which bring benefits for society, otherwise they will loose money much.

Hence, another issue we need to take care, that is, should we convert Bitcoin and other virtual currency into fiat money and how much is the exchange rate and which mechanism...that is for further researches.

\section{PROPOSAL ON IT RISK MANAGEMENT AND OPERATIONAL RISK}

In order to make Bitcoin as a digital currency and cryptocurrencies going into effect, there are many things to do to ensure no technological risk at all, and less cyber security risk: 


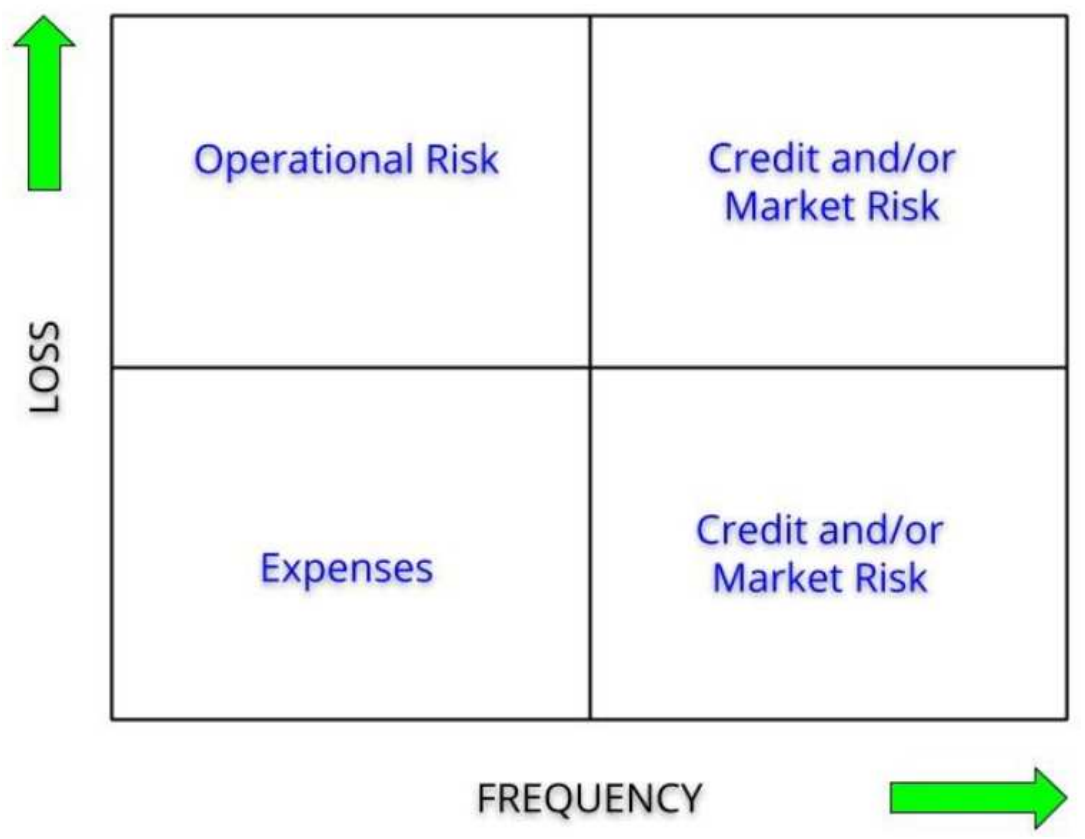

Any IT problem that happens, whether with an application, network, new system, vendor or hacker (just name a few), is likely to increase the risk for the business. Therefore, a comprehensive view of IT-based risk must put the front and center of the business into any framework or policy. Business risk includes everything (both internal or external) that affects brand, reputation, competitiveness, financial value or end status (i.e. efficiency, efficiency and its general success).

\section{THE FUTURE OF LEGAL BLOCKCHAIN SOLUTIONS.}

The experiences of various virtual currency exchanges are not optimistic in regulating them, and at the same time, as experience shows, they require a quick legislative response. Consider Japan's experience after the disastrous hacking of Mt Gox in 2014 (Legal analysis of the Tokyo District Court's decision on the insolvency of Mt Gox), and the hacking of yet another Japanese cryptocurrency exchange Coincheck in 2018 (\$ 500 million losses in cryptocurrencies. According to Fortune, the market admitted it was all due to negligent security practices.) In 2017, two markets in South Korea fell victim to cybercriminals, a two-fold attack on YouBit (losses of digital currencies worth $\$ 5.3$ million) and an attack on Bithumb (\$ 1 million loses). The Bitcurex market in Poland was hacked twice in 2014 and 2018. The second attack was worth USD 1.5 million. In 2017, it was decided to close the stock exchange without prior warning. The matter has not been clarified until today. Hacking attacks on cryptocurrency exchanges are a sad part of the history of blockchain and digital currencies. Analysis of these cyber-attacks show that they are caused by human errors, social engineering, and the lack of appropriate security rules (bitcoin.pl). As demonstrated in this article, virtual currencies and DLT systems have risks that need to be properly addressed to enhance their credibility, especially in the present circumstances. Countering these threats will require enhanced regulatory capacity, including technical expertise, and the development of a solid regulatory framework that can keep pace with innovation, enabling a commensurate and timely response when certain DLT applications become systemically important. The European Parliament resolution of 26 May 2016 on virtual currencies (2016/2007 (INI) emphasizes the importance of commensurate regulatory approaches at European Union level in order not to block innovation or burden it with unnecessary costs at an early stage, and at the same time seriously Address the regulatory challenges that the widespread use of virtual currencies and DLT can pose. On 10th of April 2018, 21 Member States and Norway agreed to sign a Declaration creating the European Blockchain Partnership (EBP) and cooperate in the 
establishment of a European Blockchain Services Infrastructure (EBSI) that will support the delivery of cross-border digital public services, with the highest standards of security and privacy. Since then, eight more countries have joined the Partnership, bringing the total number of signatories to 30. The Partnership aims to develop a trusted, secure, and resilient European Blockchain Services Infrastructure meeting the highest standards in terms of privacy, cybersecurity, interoperability, and energy efficiency, and fully compliant with EU law. The ambition of the Partnership is to make this trusted infrastructure accessible to support digital services deployed by public authorities and to support cooperation with private actors. Legal certainty is a success factor for a business to operate across the single market. The European Commission currently sees two areas related to the blockchain which could benefit from improved legal certainty:

- Smart contracts - The European Commission will study whether the current legal framework is sufficiently clear to ensure the enforceability of smart contracts and clarify jurisdiction in case of legal disputes.

- Tokenization - The European Commission will study whether the current legal framework is appropriate for issuing and trading tokens (i.e.: crypto assets) when they are not considered as financial instruments.

A 'Study on Blockchains: Legal, Governance, and Interoperability Aspects' has been launched to examine legal and regulatory aspects and socio-economic impacts of blockchain-inspired technologies. Interoperable blockchains are needed for global deployment. The European Commission is thus supporting and is engaged in work on international standardization, for DLT and blockchain particular through a liaison with ISO TC 307 on Blockchain and Distributed Ledger Technologies (ec.europa.eu/digital-single-market).

\section{ACKNOWLEDGEMENTS}

I would like to take this opportunity to express my warm thanks to Board of Editors, Professors, my family, my colleagues in assisting convenient conditions for my research paper.

\section{REFERENCES}

1. Allen, H. (2003). Innovations in retail payments: e-payments. Bank of England Quarterly Bulletin, 43(4), 428-438.

2. Caverzasi, E., Botta E., \& Capelli, C. (2019). Shadow banking and the financial side of financialization. Cambridge Journal of Econmics, 43(4)

3. Chaum, D. (1983). Blind signatures for untraceable payments. In D. Chaum, R. L. Rivest, \& A. T. Sherman (Eds.). Advances in Cryptology. Proceedings of Crypto 82, 199-203. New York, NY: Springer US. doi:10.1007/978-1-4757-0602-4

4. Christian, R. (2019). Cryptocurrencies and fundamental rights, Journal of CyberSecurity, 5(1).

5. Damodaran, A.N. (2018). The bitcoin innovation, crypto currencies and the Leviathan. Innovation and Development, 9(1).

6. Directive (EU) 2015/849 of the European Parliament and of the Council of 20 May 2015 on the prevention of the use of the financial system for the purposes of money laundering or terrorist financing, amending Regulation (EU) No 648/2012 of the European Parliament and of the Council, and repealing Directive 2005/60/EC of the European Parliament and of the Council and Commission Directive 2006/70/EC.

7. Dniprov O., Chyzhmar Y, Fomenko A., Shablystyi V., Sydorov O. (2019), Legal status of cryptocurrencyas electronic money, Journal of Legal, Ethical and Regulatory, 22 (Special Issue 2 / Business Laws and Legal Rights: Research and Practice). 
8. Genaioli, N., Shleifer, A., \& Vishny, R.W. (2011). A Model of Shadow Banking, NBER Working Paper No. 17115 Krishna, R.C. (2015). Macroeconomic Variables impact on Stock Prices in a BRIC Stock Markets: An Empirical Analysis, Journal of Stock \& Forex Trading, 4(2).

9. Giungato, P., Rana, R., Tarabella, A., \& Tricase, C. (2017). Current Trends in Sustainability of Bitcoins and Related Blockchain Technology. Sustainability, 9(12).

10. Hsieh, Y.Y., Vergne, J.P., Anderson, P., Lakhani, K., \& Reitzig, M. (2018). Bitcoin and the rise of decentralized autonomous organizations. Journal of Organization Design, 7.

11. Huy, D.T.N. (2013). Beta of Viet Nam Listed Computer and Electrical Company Groups During and After The Financial Crisis 2007-2011. Asian Journal of Finance \& Accounting, 5(1).

12. Park, C.Y., Tian, S., \& Zhao, B. (2020). Global Bitcoin Markets and Local Regulations. ADB Working Paper No.605.

13. Polish Act of March 1, 2018 on counteracting money laundering and financing of terrorism (Dz.U. 2018 poz. 723).

14. Polish Act of 23 October 2018 on the amendment the Personal Income Tax Act, the Corporate Income Tax Act, - the Tax Ordinance Act and some other acts (Dz. U. z 2018 r. poz. 2193, 2500, z 2020 r. poz. 1065).

15. European Parliament resolution of 26 May 2016 on virtual currencies (2016/2007(INI)

16. Spithoven, A. (2019). Theory and Reality of Cryptocurrency Governance. Journal of Economic Issues, 53(2). https://doi.org/10.1080/00213624.2019.1594518

17. Yuneline, M.H. (2019). Analysis of cryptocurrency's characteristics in four perspectives. Journal of Asian Business and Economic Studies, 26(2).

18. Zhou, S., Tewari, D.D., \& Sapena, J. (2019). Shadow banking, risk-taking and monetary policy in emerging economies: A panel cointegration approach, Cogent Economics \& Finance, (1).

19. https://www.sbv.gov.vn

20. https://ec.europa.eu

21. https://bitcoin.pl 